\title{
Hospital for Ophthalmia Neonatorum
}

On several occasions we have drawn attention to the necessity of making provision in large towns for the collective treatment of cases of ophthalmia neonatorum, thus following the example of Liverpool and Glasgow. It may be recalled that under the impetus afforded by the Report of the Departmental Committee on the Welfare of the Blind, issued in 1917, the Local Government Board requested the Metropolitan Asylums Board to provide hospital treatment for certain cases of the disease. The latter body arranged to establish two hospitals, one north and the other south of the Thames. One of the two institutions, formerly St. Margaret's Home, belonging to St. Pancras Union, was opened on September 15 last. It is called St. Margaret's Hospital, and is situated in Leighton Road, Kentish Town, and provides accommodation for about thirty infants and for rather more than half that number of nursing mothers. Cases are admitted on application to the central offices (Embankment, E.C. 4) in much the same way that infective diseases generally are received into the Asylums Board's other hospitals. The Board's ambulance service is available for purposes of transport. Mr. M. S. Mayou has been appointed visiting ophthalmic surgeon, and Dr. C. G. May, visiting gynaecologist to the new institution.

\section{ABSTRACTS}

\section{I.-THE EVOLUTION OF LIGHT AND. OF COLOUR SENSE}

Hess, C. (Munich).-The evolution of light sense and colour sense in the animal kingdom.

Hess delivered a lecture on the evolution of light and colour sense in the animal kingdom at the Eighty-fifth Congress of the Society of German naturalists and medical men held in Vienna in 1913, a translation of which has kindly been furnished to us by Mr. D. V. Giri. The pressure on our space prevents us from publishing it in full. Hess insists on the importance of working with proper spectral colours the luminosity of which is sufficiently accurately known for the human eye under different conditions. He gives details of various experiments carried out with different animals. In dealing with vertebrates he tested monkeys by putting grains of rice on a black surface and illuminating them with the spectrum. The monkey picked up the grains of rice exactly as a human eye 